\title{
GCU
}

Glasgow Caledonian

University

University for the Common Good

\section{Practices of Nigerian physiotherapists with respect to lifestyle risk factor assessment and intervention: a national cross-sectional survey}

Abaraogu, Ukachukwu Okoroafor; Ogaga, Mary Oguma; Dean, Elizabeth

Published in:

Physiotherapy Theory and Practice

DOI:

10.1080/09593985.2017.1318421

Publication date:

2017

Document Version

Author accepted manuscript

Link to publication in ResearchOnline

Citation for published version (Harvard):

Abaraogu, UO, Ogaga, MO \& Dean, E 2017, 'Practices of Nigerian physiotherapists with respect to lifestyle risk factor assessment and intervention: a national cross-sectional survey', Physiotherapy Theory and Practice, vol. 33, no. 6, pp. 497-507. https://doi.org/10.1080/09593985.2017.1318421

\section{General rights}

Copyright and moral rights for the publications made accessible in the public portal are retained by the authors and/or other copyright owners and it is a condition of accessing publications that users recognise and abide by the legal requirements associated with these rights.

Take down policy

If you believe that this document breaches copyright please view our takedown policy at https://edshare.gcu.ac.uk/id/eprint/5179 for details of how to contact us. 
Current practices of Nigerian physiotherapists with respect to lifestyle risk factor assessment and intervention: A national cross-sectional survey

Authors: ${ }^{1}$ Ukachukwu Okoroafor ABARAOGU, ${ }^{1}$ Mary Oguma Ogaga, ${ }^{2}$ Elizabeth Dean

\section{Affiliations}

${ }^{1}$ Department of Medical Rehabilitation, University of Nigeria, Enugu, Nigeria.

${ }^{2}$ Department of Physical Therapy, University of British Columbia, Vancouver, Canada.

Correspondence: *Abaraogu Ukachukwu Okoroafor | Department of Medical Rehabilitation Faculty of Health Science and Technology College Medicine University of Nigeria Enugu

Campus Enugu 400006 Enugu Nigeria | ukachukwu.abaraogu@unn.edu.ng 


\section{Abstract}

Background: Resolutions of the World Health Organization and World Confederation for Physical Therapy declare health promotion a priority for health professionals including physiotherapists. Objective: To describe lifestyle-related risk factor assessment and intervention practices of Nigerian physiotherapists, their perceived barriers to such practices, and education needs. Methods: Physiotherapists $(\mathrm{n}=650)$ were invited to complete a questionnaire with 23 questions about their lifestyle, family history, and anthropometric risk factor examination/assessment and intervention practices; barriers to such practices; and related education needs. Statistical analysis was descriptive. Results: Response rate was 69\% $(\mathrm{n}=451)$. Less than half of respondents always advised smokers to quit, or heavy drinkers to reduce alcohol consumption. Most respondents viewed diet and anthropometrics as risk factors that warrant being addressed but few respondents do so. Physical inactivity and blood pressure were the commonest risk factors assessed. Perceived barriers to health promotion practices included time, knowledge, and access to other providers. Continuing education needs identified by respondents included smoking cessation, and delivering dietary and alcohol consumption advice. Conclusions: Nigerian physiotherapists inconsistently assess lifestyle-related risks and intervene to address them. Continuing education is needed to 
address barriers to health promotion practices and reduce the gap between their perceived and actual continuing education needs.

Keywords Physiotherapists, assessment and management of lifestyle risk factors, smoking, nutrition, alcohol consumption, physical activity, prevention of non-communicable diseases

\section{$\underline{\text { BACKGROUND }}$}

In 1998, a World Health Organization (WHO) resolution advocated the adoption of an evidence-based approach to health promotion policy and practice (World Health Organization, 1998). The WHO not only promotes capacity strengthening within its member countries, but also through international collaborative partnerships including between developing and developed countries (World Health Organization, 2004; World Health Organization, 2014a).

The World Confederation for Physical Therapy has strongly advocated that its member countries be proactive in health promotion practice (World Confederation for Physical Therapy, 2014). Furthermore, two physiotherapy summits on global health have advocated a primary role for physiotherapists in addressing lifestyle-related noncommunicable diseases (NCDs) and recommending competencies they need to effect lifestyle behavior change regardless of the reason for referral to physiotherapy (Dean, 2009; Dean et al, 2011; Dean et al, 2013). Given any adverse lifestyle factor (e.g., improper diet, alcohol use, tobacco use, and physical inactivity) can compromise treatment outcomes, it can be argued that any presenting diagnosis provides justification for including lifestyle counseling within the patient's plan of care. African countries appear to be following trends in western 
countries with now at least two of the ten leading causes of death in the region being lifestyle-related NCDs compared with several in developed regions (Dean et al, 2011; World Health Organization, 2011).

Compared with developed countries, the status of physiotherapists' assessment and management of risk factors for NCDs in developing countries such as Nigeria has received less attention. In the United States, Rea and colleagues (2004) examined the perceptions of 417 physiotherapists in three states about the role of health promotion in their practices. They observed that a physiotherapist's confidence to perform health promotion competencies was the best predictor of performing them. Other investigators have examined this topic in relation to the status of health promotion by physiotherapists in early childhood (Goodgold, 2005) and for the older adult (Healey et al, 2012). These studies conclude that health promotion practice by American physiotherapists is varied.

A Canadian study investigated the self-efficacy of physiotherapists $(n=738)$ in relation to smoking cessation counseling (Bodner et al, 2011). Although respondents acknowledged the importance of smoking assessment and cessation; they reported a lack of competency. In another study in a developing country, Nigeria, Aweto and colleagues (2013) studied the knowledge, attitudes, and practices of physiotherapists $(n=380)$ regarding the promotion of active living in patients. Like Canadian physiotherapists, Nigerian physiotherapists had good knowledge (64\%) and positive attitudes $(95 \%)$ towards activity promotion, but few reported counseling more than ten patients in the past month about being more physically active (36\%). The findings supported physiotherapists' integrating brief counseling and recommendations about physical activity within the context of a patient's treatment, despite apparent limited time. Integrating counseling that is brief within a standard visit was reported by the physiotherapist respondents as the most expedient means of promotion physical activity within patient management. 
A recent seminal Irish study reported by O’Donoghue and colleagues (2014) examined the activities, barriers and continuing education needs of physiotherapists, with respect to assessing and managing lifestyle risk factors. The investigators examined lifestyle risks including smoking, unhealthy diet, alcohol abuse, and inactivity. Not surprisingly, the investigators observed that physical activity was the commonest risk assessed by three quarters of respondents and diet by half of them. Smoking and alcohol abuse were reported to be addressed less by respondents due to limited time and expertise, and belief that addressing such lifestyle factors was not their role. Both this study as well as the Canadian study concluded physiotherapists would benefit from increased competencies in the systematic assessment of and interventions related to lifestyle risk factors.

Given the increasing prevalence of NCDs in Nigeria and the call to mobilize the healthcare workforce to address them (World Health Rankings, 2015; World Health Organization, 2011; World Health Organization, 2014b; Health Reform Foundation of Nigeria, 2011; Ekpenyong et al, 2012), we extended the study by O'Donoghue et al (2014) to the Nigerian context. Our objective was to investigate practices related to the assessment and management of lifestyle-related NCD risks by Nigerian physiotherapists, and their perceived barriers to such practices and related education needs. Such a baseline would establish the status of health promotion practices in the Nigerian physiotherapy community and provide directions for establishing health promotion practice as a bone fide physiotherapy competency. Our findings could help advance the WHO's mandate and future initiatives for reducing NCDs in Nigeria, through collaboration and shared experiences and knowledge about NCD physiotherapy management in developed countries.

\section{$\underline{\text { METHODS }}$}

\section{$\underline{\text { Design and ethics }}$}


This descriptive study was based on a national cross-sectional survey. The study was approved by the institutional ethical review board of the University of Nigeria Teaching Hospital, in order to provide assurance of protection of human subjects. Informed consent was received from each participant prior to completion of the anonymous questionnaire. Participants provided voluntary signed consent prior to completing the questionnaire.

Confidentiality was assured with removal of identifying information.

$\underline{\text { Sample }}$

We sampled Nigerian physiotherapists' practicing part- and full-time in both private and public health sectors. The Medical Rehabilitation Therapist Board of Nigeria directory of licensed physiotherapists as well as the register of the Nigerian Society of Physiotherapy provided the number of physiotherapists practicing in Nigeria at the time of the study, and their contact information within their provisions of information security and confidentiality.

We used a sample of convenience. Participants were volunteers from the various regions of the country Table 1 . Given a level of confidence of 0.05 , a confidence interval of \pm 5 , a total population size of 1009 Nigerian physical therapists, and an effect size of 1.5 (Gorstein et al, 2007), at least 417 respondents were needed.

\section{Procedure}

Questionnaires were distributed to physiotherapists across hospitals, medical/health centers and clinics in 21 states and the federal capital territory of Nigeria between March and July 2014. The distribution of questionnaires across states and geopolitical zones are shown in Table 1.

Questionnaires were emailed to individuals who administered them in places where the principal investigator could not be present. If no email address was available, 
questionnaires were couriered to physiotherapy department heads, heads of clinics, or designated contact physiotherapists. A total of 650 were distributed.

\section{Questionnaire}

The questionnaire used in this study is a validated tool for assessing risk assessment and risk management practices of physiotherapists. It was initially designed by Laws and colleagues (2008) and modified by O'Donoghue and colleagues (2014) with permission. The questionnaire uses a 4-point Likert-like scale to assess 23 items across 5 domains. The first domain was the assessment of risk factors, namely, smoking, diet, alcohol consumption, physical activity/exercise, blood pressure, family history of cardiovascular disease/diabetes, and anthropometrics. Respondents were asked to indicate the frequency with which they assess each of the risk factors in practice based one of the following categories: never, sometimes, usually, or always.

The second domain was management of risk factors in patients in whom the respondents had identified one or more of four lifestyle risk factors, i.e., smoking, poor diet, alcohol consumption, and inactivity. Respondents were asked to indicate the frequency with which they address or intervene with respect to each of the listed risk factors in practice (i.e., readiness to change, advise, give written advice, refer to other services/providers, and ability to find other services/providers) based on one of the following categories: never, sometimes, usually, or always.

The third domain related to physiologic risk factors. In this domain, respondents were asked to identify the frequency with which they recommend specific lifestyle changes in patients with diagnoses of overweight/obesity, glucose intolerance, hypertension, and hyperlipidemia. Behavior change options included fewer calories, less dietary fat, increased dietary fiber, regular exercise, and setting a weight loss goal. Frequency categories were never, sometimes, usually, and always. 
The fourth domain related to lifestyle counseling. With respect to importance of counseling for health behavior change, i.e., smoking cessation, healthy diet, alcohol moderation, and increasing activity, the response categories were very important, moderately important, somewhat important, and not very important. With respect to the respondents' perceptions of the acceptability of these four lifestyle behavior changes as part of their physiotherapy consultations, the response categories were very acceptable, moderately acceptable, somewhat acceptable, and not acceptable. With respect to the acceptability of the four lifestyle behavior changes as part of the respondents' routine practice, the response categories were high priority, moderate priority, somewhat of a priority, and low priority. With respect to how effective respondents believed their lifestyle behavior change attempts were, the response categories were very effective, somewhat effective, and not effective (with a final option of 'no advice provided'). With respect to respondents' confidence in specific lifestyle behavior change interventions (i.e., assessing nicotine dependence, nutritional status, risky drinking, physical inactivity, readiness to change, and absolute cardiac risk; and motivational interviewing), the response categories were very confident, moderately confident, somewhat confident, and not confident. Finally, in this domain, respondents were asked to identify the degree to which they agreed with five lifestyle behavior change belief statements, with response categories being strongly agree, somewhat agree, disagree, and strongly disagree.

The fifth domain consisted of barriers to assessing and managing lifestyle risk factors. Barriers listed were lack of time, lack of access to health promotion counselors/services, personal lack of interest, patient lack of interest, uncertainty about services to provide, insufficient patient education resource materials, and lack of expertise. Response categories were significant barrier, somewhat of a barrier, and not a barrier. A final response category was not applicable. A second component of this domain was the identification of barriers (as 
above in a checklist) to specific lifestyle behavior changes, i.e., smoking cessation, dietary advice, alcohol consumption advice, and physical activity advice.

The last section of the questionnaire was related to respondents' training and professional education over the past year, on assessing risk factors and their management with respect to effecting health behavior change. The response options were either yes or no for each of the following professional education topics: smoking cessation; assessment and intervention (systematic and personalized advice) for nutrition, physical activity, and alcohol use; motivational interviewing; assessing readiness to change lifestyle behavior; patient education strategies; managing blood pressure; managing hyperlipidemia/dyslipidemia; measuring anthropometrics; prevention of cardiovascular disease; prevention of diabetes; and reducing cardiovascular risk.

With respect to the delivery of health behavior change content, respondents were asked whether they would like to receive further continuing education on these topics and, if so, in what format.

\section{$\underline{\text { Data analysis }}$}

Data were analyzed using SPSS version 15 (IBM Corp. New York, USA), with descriptive statistics (frequencies and percentages) used to summarize the findings. Alpha was set at 0.05 .

\section{$\underline{\text { RESULTS }}$}

Study results are described relative to the content of the questionnaire and include: respondent demographics; assessment of risk factors; management of risk factors including lifestyle counseling; barriers to assessing and managing lifestyle risk factors; and education needs.

\section{$\underline{\text { Respondent demographics }}$}


Some 451questionnaires were completed (response rate 69\%). Two thirds of respondents were men (67\%) with the 35-44 y age group having most respondents (42\%). Most (92\%) practiced primarily in orthopedics yet provided services in other areas as needed, i.e., neurological, pediatric, and cardiopulmonary, and women's health. Participants reported having held their current positions from 1 to $22 \mathrm{y}$. Based on national data, our sample represented the demographics of physiotherapists in the country (The Medical Rehabilitation Therapist Board of Nigeria, 2011).

\section{$\underline{\text { Assessment of risk factors }}$}

Over half of respondents 'always' assessed smoking status (56\%), alcohol consumption (55\%), and family history of cardiovascular disease/diabetes (55\%). Less than half of respondents reported 'always' (47\%) assessing physical activity, and that they 'sometimes' assessed diet (39\%) and anthropometrics (42\%) (Table 2). Blood pressure was the most commonly assessed risk factor during the patient's initial assessment, with more than two thirds of respondents measuring it (71\%).

At follow-up visits, respondents were less likely to assess risk factors than at initial visits (Table 2). More respondents reported that they 'sometimes' assess diet (41\%) and anthropometrics (40\%) in follow-up patients. Smoking, alcohol abuse, and anthropometrics were risk factors most likely not to be assessed. Compared with new patients, activity assessment was about the same at follow-up with less than half reporting that they 'always' (47\%) or 'usually' (27\%) assess physical activity. Blood pressure remained the only risk factor that most respondents identified as performing 'always ' (63\%).

\section{Management of risk factors including lifestyle counseling}


Although smoking is the risk factor that most respondents reported they 'never' (16\%) assessed, over half reported regularly ('usually' or 'always') assessing patients' readiness to change behavior and quit (56\%). Readiness to change behavior, i.e., increase physical activity however, was 'always' assessed by just less than half (47\%) of respondents and regularly by three quarters (78\%). Overall, $84 \%$ to $96 \%$ of respondents reported that they' sometimes', ‘usually' or 'always' assessed readiness to change in all four risk factors (Table 3).

With respect to advising against risky lifestyle behaviors (Table 3), about half of respondents 'always' advised patients to stop smoking (45\%), increase fruit and vegetable intake (49\%), and decrease alcohol intake (49\%). One third of respondents reported having 'always' or 'usually' advised patients to increase their fiber intake. Almost two thirds of respondents (62\%) reported they 'always' advised patients to be regularly active and exercise.

Written advice on being active was the most written type of advice given by the participants 'always' (23\%) (Table 3). However, the number that 'never' (24\%) gave written advice is slightly greater. Half of respondents 'never' (51\%) gave written advice about smoking cessation. Related to healthy diet and alcohol consumption, a greater number reported that they hardly (defined as 'never' or 'sometimes') provided written advice.

In terms of referring patients to other providers or services which may reflect accessibility to these services (Table 3), half of respondents did not refer to others for smoking cessation (51\%) and alcohol abuse programs (48\%) with about the same number reporting they did not find accessible services/providers to address specific risk factors. One third of respondents referred patients 'sometimes' (34\%) for dietary programs and 'always' (34\%) for exercise programs. Providers for dietary and exercise programs were most easily accessible, but about one quarter 'regularly' accessed other services for onward referral. 
The source of educational materials distributed to patients by the respondents was mostly from professional bodies ranging from $21 \%$ to $48 \%$ and from government sources ranging from $8 \%$ to $16 \%$ depending on the health behavior. Many respondents however provide no resource materials to their patients, ranging from $21 \%$ to $48 \%$ depending on the health behavior.

In addressing lifestyle risk factors, overweight/obesity, impaired glucose tolerance, hypertension, and hyperlipidemia were considered (Table 4). Regarding obesity, almost all respondents (99\%) recommended consuming fewer calories. Most respondent 'always' recommended regular exercise (71\%) and over half' always' advised dietary changes, i.e., reduce dietary fat and increase fiber intake, and set weight loss goals. Only $2 \%$ did not advise regular exercise for hypertensive patients. Half of respondents 'always' (49\%) advised regular exercise and $41 \%$ 'always' advised increased fiber intake for patients with impaired glucose tolerance. For patients with hyperlipidemia, half of respondents recommended regular exercise and $43 \%$ ) recommended less fat intake with about the same rate for increased fiber intake.

Table 5 shows respondents' views about lifestyle counseling, i.e., its relevance to their practices and its perceived importance to their patients. Most respondents thought it was very important to counsel for all modifiable risk factors (ranged from $84 \%$ to $86 \%$ depending on the risk factor) with somewhat fewer acknowledging the important for advising about alcohol consumption, with 79\% saying it was 'very important'. Respondents reported that patients generally found counseling acceptable especially regarding healthy diet and physical activity/exercise. Over half of respondents considered addressing all four lifestyle risk factors as part of clinical practice as a priority, and many are confident in assessing risk factors especially physical inactivity (67\%) (Table 6). Respondents reported being least confident in assessing nicotine dependence; about one third reported being 'very confident' (34\%). Most 
reported their advice was very effective especially concerning physical activity (71\%) (Table 6).

With respect to their beliefs about their professional self-efficacy to effect behavior change and the perceived self-efficacy of their patients to change, respondents believed health behavior change is an effective use of their time (76\%). An overwhelming proportion of respondents (95\%) agreed that most patients will change their lifestyle if they advise them to do so. In terms of their confidence to promote health in their patients compared with other health professionals, most disagreed with the statement that others were superior $(78 \%)$. However despite respondents' positive views about effecting health behavior change in their patients, $62 \%$ of respondents acknowledged that health outcome does little to promote adherence to healthy lifestyles by their patients.

\section{Barriers to assessing and managing lifestyle risk factors}

Table 7 shows the perceived barriers preventing respondents from providing lifestyle interventions for the four lifestyle risk factors. Although most respondents have personal interest in providing lifestyle interventions $(65 \%)$ and were confident about what services to provide $(61 \%), 31 \%$ reported that involvement in lifestyle risk assessment and management was severely limited by time. The most commonly-cited barriers ('significant' and 'somewhat') to assessing and managing lifestyle risk factors were lack of patient education materials (77\%), perceived lack of interest of the patient (67\%), lack of access to health promotion staff/counselors (65\%), and limited time (61\%).

\section{$\underline{\text { Respondents' education needs }}$}

Over the year prior to the study, over half of respondents reported having access to continuing education related to health promotion courses related to nutrition; physical activity; managing blood pressure; measuring anthropometrics; and preventing cardiovascular 
risk and disease, and type 2 diabetes mellitus. Over this timeframe, less than half of respondents reported having access to continuing education related to health promotion courses related on smoking cessation; alcohol abuse; motivation interviewing; assessing patients' readiness to change; patient education strategies; and managing hyperlipidemia. The area in which most training had occurred was physical activity (68\%). The areas in which respondents had received the least training were smoking cessation (36\%), alcohol consumption (40\%), assessing patients' readiness to change (41\%), managing hyperlipidemia/dyslipidemia (40\%), and patient education strategies (42\%). Most respondents (96\%) reported that they would like more training mostly in workshop format (73\%), with least interest in training through clinical supervision (16\%) and self-study materials $(6 \%)$.

\section{DISCUSSION}

To our knowledge, this is the first WHO-informed study in Africa to focus on the physiotherapist's role in addressing lifestyle-related risk factors for NCDs and related professional education needs. O'Donoghue and colleagues (2014) who recently studied this among physiotherapists in the Republic of Ireland argued that their findings highlighted an important untapped potential with respect to the role of physiotherapists addressing lifestylerelated risk factors in their daily practices. Respondents to their questionnaire identified barriers such as limited time and expertise in being able to effect lifestyle behavior change in their patients. The investigators concluded that although Irish physiotherapists are well positioned to address the prevalence of lifestyle-related NCDs within the aging population and increasingly in the young population, changes need to be made within physiotherapy practice patterns to address the time concern, and continuing education is needed to teach essential competencies in health promotion practice. Finally, they argue that promoting health and wellness needs to be addressed at multiple levels including legislative, practice standards 
development, and professional education curriculum and continuing education. Our findings establish a baseline for Nigeria related to physiotherapists' addressing NCD risk factors, in addition to providing a basis for comparing findings across countries, which remains limited. The need for time and expertise are recurring themes (Bodner et al, 2012; Rea et al, 2004) suggesting institutional change is also needed to address these broad-based societal professional issues.

Our findings support that Nigerian physiotherapists regularly, but perhaps inconsistently, assess risk factors related to smoking status, diet, alcohol consumption, physical activity, blood pressure, and family history of cardiovascular diseases and diabetes, and anthropometics. Overall, this is an encouraging finding given early detection of risk factors is key to preventing/addressing lifestyle-related NCDs.

Although assessment of risk factors is essential, this is insufficient without being conducted systematically and followed up with targeted interventions. Respondents however reported lacking expertise to address or manage modifiable risk factors. O'Donoghue and colleagues (2014) reported similar findings among Irish physiotherapists stating that they too lack expertise and experience in addressing smoking, diet and alcohol consumption; three key risk factors for lifestyle-related NCDs, e.g., type 2 diabetes and cardiovascular disease. With respect to smoking cessation, at least in the Canadian context, physiotherapists report lacking confidence in health behavior change (Bodner et al, 2012). With the possible exception of self-efficacy in promoting physical activity for health, we presuppose that physiotherapists are generally less confident, thus have less self-efficacy, in promoting other healthy lifestyle behaviors and effecting long-term lifestyle behavior change. The development of universallyagreed standardized health promotion competencies within physiotherapy practice (with 
minimum standards) would ensure an established level of self-efficacy, comparable to conventional physiotherapy interventions and practices (Dean et al, 2014).

No literature exists regarding benchmarks for clinical competencies in lifestyle behavior health promotion among physiotherapy education programs in Nigeria. Data from developed countries (Bodner et al, 2013) suggest that apart from limited hours of theoretical instructions, practical and clinical sessions required for practice competency in addressing modifiable risk factors are generally not included in the entry-level curriculum of physiotherapy programs. Given continuing professional education is a primary vehicle for increasing physiotherapists' competencies in health promotion practice (examination/assessment and intervention), universally-agreed competencies with minimal standards, warrant being established to ensure the rigor of practice competencies are uniform comparable to conventional physiotherapy practices.

Based on our findings, Nigerian physiotherapists regard physical activity and exercise prescription as core in patient management; they reported being very confident and proficient in activity/exercise prescription. Relatively few however assessed physical activity regularly in their initial consultation; with only half reporting they 'always' advise on regular exercise in managing modifiable risk factors. In their study related to Nigerian physiotherapists' knowledge, attitudes and practices towards promoting a physically-active lifestyle, Aweto and colleagues (2013) reported that they have good knowledge and positive attitudes towards promoting active lifestyles in their patients but tend not to counsel them. Physiotherapists appear not to be addressing physical inactivity even when they report having the expertise and express confidence and interest in doing so. Given that inactivity constitutes a major risk for coronary heart disease and type 2 diabetes (Council on Foreign Relations, 2015), physiotherapists need competencies in health behavior change including increasing physical 
activity. An examination of perceived barriers reported by physiotherapists to effect health behavior change sheds light on how to address this discrepancy. Aweto and colleagues (2013) reported that most Nigerian physiotherapists identified limited time as a barrier to promoting active lifestyle among patients; this was similar in our study.

Regarding nutrition, that most respondents reported that they advised their patients to increase fiber, fruit and vegetable intake is positive. Only half of respondents however reported regularly assessing dietary status in their initial consultations and follow-ups. This suggests that respondents may arbitrarily give basic dietary advice to patients without dietary assessment. With respect to intervention, most respondents do not provide written advice even though they consider this to be very important and themselves effective at giving such advice. O'Donoghue and colleagues (2014) reported similar findings in their cohort of Irish physiotherapists regarding assessment of nutritional status, but observed that few respondents provided interventions. Thus, unlike primary care Irish physiotherapists, most Nigerian physiotherapists regularly provide dietary interventions, albeit unwritten, as part of standard practice.

Few studies have examined practices of health professionals outside their own areas. One exception is a survey study in which Canadian dieticians reported that they routinely promote physical activity to their clients (Johnson et al, 2007). Such findings support a precedent for health professionals' integrating basic lifestyle counseling into their practices, even though such counseling is not typically considered their role. In our experience, Nigerian physiotherapists seldom practice outside traditional professional boundaries. Universally agreed standards related to health promotion practice competencies in physiotherapy need also to include assessment of need, basic health behavior change 
interventions, outcome evaluation, progression criteria, and knowledge of when to refer to other providers and services.

Anthropometrics was another risk factor that is opportunistically assessed at initial and follow-up assessments by Nigerian physiotherapists. Again, most respondents in our study reported that they recommend fewer calories and fat to patients who are overweight unlike a minority of physiotherapists in a related Australian study (Snodgrass et al, 2007). Nevertheless, like Australian physiotherapists, most set a goal for weight loss including regular exercise. This is a positive finding given that a patient's body mass is highly associated with the incidence of NCDs. Assessing anthropometric variables including body mass index, waist girth and waist-to-hip ratio are warranted as a basis for initiating basic advice about nutrition coupled with exercise, or referral to a nutritionist/dietician.

Many physiotherapists in our study assessed patients' smoking and alcohol consumption status with new patients because they consider these behaviors very important, however these two risk factors were the most frequently overlooked with respect to intervention, with the majority neither regularly providing written advice nor regularly referring their patients to other health professionals. Lack of access to services could be a barrier, given most respondents were also unable to access services for smoking cessation and alcohol abuse. To promote assessment of lifestyle behaviors such as smoking and alcohol consumption, physiotherapists are more likely to do so if there are accessible services and resources (Bodner et al, 2012).

Responding to epidemiological priorities in physiotherapy practice has been strongly advocated (Dean et al, 2011; Dean et al, 2013). Smoking cessation in physiotherapy practice is not common (Bodner et al, 2012) despite its endorsement as a professional responsibility in several countries (Pignataro et al, 2012; Canadian Physiotherapy Association, 2008; 
Chartered Society of Physiotherapy, 2012). Further, physiotherapists' addressing alcohol abuse has received little attention. Studies of general practitioners and nurses have reported the effectiveness of screening combined with a brief intervention and written information for clients with alcohol dependency (Rose et al, 2008; Saitz, 2010; Kaner et al, 2013). Such an approach warrants being integrated into physiotherapy practice.

The major barrier that Nigerian physiotherapists encounter concerning risk factor assessment is time limitation. In addition, most respondents considered insufficient resource material, patient interest, and access to health providers for onward referral, as barriers to providing lifestyle behavior change interventions. This finding calls for a multimodal approach to addressing barriers to effective lifestyle behavior change. Addressing the issue of limited time in the Nigerian context, Aweto and colleagues (2013) recommended that health policy makers, clinic managers and heads of physiotherapy clinics who are in positions to stipulate physiotherapists' time allocations with patients, be advised on planning clinics such that patient consultations include lifestyle counseling. Other investigators have concurred that incorporating physical activity advice into physiotherapy consultations is feasible (O'Donoghue et al, 2014; Shirley et al, 2010), and this could be extended to health advice and promoting lifestyle behavior change.

Regarding NCD education material, professional bodies, governments, nongovernmental organizations and other stakeholders need to commit to making lifestyle education materials available to healthcare practitioners including physiotherapists, and healthcare practitioners seek out these valuable evidence-based resources. Further, healthcare practitioners need to practice collaboratively to maximize outcomes in patient health and ensure that health behavior change initiatives are seamless and reinforced across the health professionals that a patient may be seeing (Dean et al, 2014). 
Over the past year, most study participants reported having had continuing education on physical activity and exercise, diabetes prevention, prevention/management cardiovascular disease, and hypertension management. Most lacking was continuing education for smoking cessation, alcohol abuse, hyperlipidemia management, as well assessment of patients' readiness to change, patient education strategies, and motivational interviewing. It is unclear whether these opportunities were unavailable or not selected by the participants. We strongly argue in favor of physiotherapists' having clinical competencies in these areas that adhere to stringent universally agreed practice standards. With little additional time, brief lifestyle counseling constitutes substantial 'value added' to patient care (Pignataro et al, 2012). Healthy lifestyles not only maximize patients' health, but also have the potential to augment outcomes of conventional physiotherapy and biomedicine (O'Donoghue et al, 2014).

The capacity to conduct cross-cultural comparisons is limited at this time and should be expanded in future research. The few studies that have been reported are not directly comparable, thus limit drawing conclusions. The earliest study by Rea and colleagues (2004) for example focused on health promotion by physiotherapists in three American states. This study published over ten years ago may not be representative of the United States in general or of the status of health promotion practice of physiotherapists today. Although the study by Aweto and colleagues (2012) is more recent, it examined attitudes and health promotion practices of Nigerian physiotherapists that focused on physical activity only. The most comprehensive study to date is that of O'Donoghue and colleagues (2014) who examined assessment and management practices of several lifestyle-related NCD risk factors by Irish physiotherapists, in addition to their perceived barriers and training needs. Given the rigor and recency of their study, we chose to replicate and extend it to the Nigerian context, thereby, expanding and building the body of comparative literature in the area. 
Our study has limitations. Being a questionnaire study, the data rely on self-reports. This study provides data sample estimates for future studies that were not in place for this. The questionnaire could be improved in some ways. Anthropometrics for example was unspecified in the original questionnaire. We assumed it to mean body composition measures such as body weight and height, and calculation of body mass index. Future use of this questionnaire needs to operationalize the term to avoid ambiguity.

\section{CONCLUSIONS}

Our findings have established a baseline of health promotion practices by physiotherapists in Nigeria. While inactivity and blood pressure were most highly identified as being assessed, little intervention was initiated, comparable to the Irish data. Otherwise, diet, alcohol consumption, and anthropometrics were variably assessed or served as a basis for intervention in both contexts. Comparably, perceived barriers such as limited time and expertise were identified as limiting health promotion practice. This finding serves as a basis for revising physiotherapy education and developing continuing education. Finally, the Nigerian data supports the Irish data in that universally agreed and established health promotion competencies in physiotherapy are needed. In addition, within the Nigerian context, there is a need to reconcile the gap between what physiotherapists perceive as their continuing education needs and their actual needs. Given the paucity of comparative data, replication and extension studies are needed in other countries. These will not only serve as a basis for cross country comparisons, but also, with respect to revision of physiotherapy curricula and continuing education programs, changes in health promotion practices within countries can be evaluated. 


\section{ACKNOWLEDGEMENT}

The authors gratefully acknowledge G. O’Donoghue, C. Cunningham, F. Murphy, C. Woods, and J. Aagaard-Hansen for permission to use their questionnaire to extend their work conducted in the physiotherapy community of the Republic of Ireland to Nigeria.

\section{DECLARATION OF INTEREST}

The authors report no conflicts of interest. The authors alone are responsible for the content and writing of this article. 


\section{REFERENCES}

Aweto HA, Oligbo CN, Fapojuwo OA, Olawale OA 2013 Knowledge, attitude and practice of physiotherapists towards promotion of physically active lifestyles in patient management. BMC Health Service Research13: 21

Bodner ME, Miller WC, Rhodes RE, E Dean 2011 Smoking cessation and counseling: knowledge and views of Canadian physical therapists. Physical Therapy 91: 1051-1062

Bodner ME, Rhodes RE, Miller WC, Dean E 2012 Smoking cessation and counseling practices of Canadian physical therapists. American Journal of Preventive Medicine 43: 6771

Bodner ME, Rhodes RE, Miller WC, Dean E 2013 Benchmarking curriculum content in entry-level health professional education with special reference to health promotion practice in physical therapy: a multi-institutional international study. Advances in Health Science Education 18(4): 645-657

Canadian Physiotherapy Association 2008 Tobacco: the role of health professionals in smoking cessation. Joint statement.

www.physiotherapy.ca/public.asp? $\mathrm{WCE}=\mathrm{C}=47|\mathrm{~K}=222537| \mathrm{Refresh} \mathrm{T}=222559 \mid \mathrm{RefreshS}=\mathrm{Left}$ Nav RefreshD $=2225592$

Chartered Society of Physiotherapy 2012 Brief interventions: evidence briefing (part of the public health and physiotherapy resource pack - physical activity, smoking cessation, obesity, alcohol and falls prevention). http://www.csp.org.uk/publications/publichealthphysiotherapy- resource-pack-part-4-brief-interventions-evidence-briefing

Council on Foreign Relations 2015 The Emerging Global Health Crisis. Noncommunicable Diseases in Low- and Middle-Income Countries Task Force. http://www.cfr.org/diseasesnoncommunicable/emerging-global-health-crisis/p33883

Dean E 2009 Physical therapy in the 21st century (Part I): toward practice informed by epidemiology and the crisis of lifestyle conditions. Physiotherapy Theory and Practice 25: 330-353

Dean E, Al-Obaidi S, Dornelas de Andrade A, Gosselink R, Umerah G, Al-Abdelwahab S, Anthony J, Bhise A, Bruno S, Butcher S, Olsen M, Frownfelter D, Gappmaier E, Gylfadottir S, Habibi M, Hasson S, Jones A, Lapier T, Lomi C, Mackay L, Mathur S, O'Donoghue G, Playford K, Angroula K, Scherer S, Skinner M, Wong WP 2011 The First Physical Therapy Summit on Global Health: implications and recommendations for the 21st century. Physiotherapy Theory and Practice 27: 531-547

Dean E, Dornelas de Andrade A, O’Donoghue G, Skinner M, Umereh G, Beenen P, Cleaver S, Afzalzada D, Delaune MA, Footer C, Gannotti M, Gappmaier E, Figl-Hertlein A, Henderson B, Hudson MK, Spiteri K, King J, Klug JL, Laakso E-L, LaPier T, Lomi C, Maart S, Matereke N, Meyer ER, M'kumbuzi VRP, Mostert-Wentzel K, Myezwa H, Fagevik Olsen M, Peterson C, Petursdottir U, Robinson J, Sangroula K, Stensdotter A-K, Tan BY, 
Tschoepe BA, Bruno S, Mathur S, Wong WP 2013 The Second Physical Therapy Summit on Global Health: developing an action plan to promote health in daily practice and reduce the burden of non-communicable diseases. Physiotherapy Theory and Practice Early Online: 115. doi: $10.3109 / 09593985.2013 .856977$

Dean E, Moffat M, Skinner M, Dornelas de Andrade A, Myezwa H, Söderlund A 2014 Toward core inter professional health promotion competencies to address the noncommunicable diseases and their risk factors through knowledge translation: curriculum content assessment. BMC Public Health 14: 717

Ekpenyong CE, Udokang NE, Akpan EE, Samson TK 2012 Double burden, noncommunicable diseases and risk factors evaluation in sub-Saharan Africa: the Nigerian experience. European Journal of Sustainable Development 1: 249-270

Goodgold S 2005 Wellness promotion beliefs and practices of pediatric physical therapists. Pediatric Physical Therapy 17(2): 148-157

Gorstein J, Sullivan KM, Parvanta I, Begin F. Indicators and methods for cross-sectional surveys of vitamin and mineral status of populations. Micronutrient Initiative (Ottawa) and Centers for Disease Control and Prevention (Atlanta), May 2007, p 29).

Healey WE, Broers KB, Nelson J, Huber G 2012 Physical therapists' health promotion activities for older adults. Journal of Geriatric Physical Therapy 35(1): 35-48

Health Reform Foundation of Nigeria (HERFON) 2011 Diabetes to top cause of death in 2015. HERFON Bulletin 4: 38-39

Johnson ST, Bates H, Fitzpatrick J, Marshall JD, Bell RC, McCargar L 2007 Promotion of physical activity by Canadian registered dieticians in daily practice. Journal of Human Nutrition and Dietetics 20: 37-40

Kaner I, Bland M, Cassidy P, Coulton S, Dale V, Deluca P, Gvarry E, Godfrey C, Heather N, Myles J, Newbury-Birch D, Oyefeso A, Parrott S, Perryman K, Phillips T, Shepherd J, Drummond C 2013 Effectiveness of screening and brief alcohol intervention in primary care (SIPS trial): pragmatic cluster randomized controlled trial. British Medical Journal 346: e8501. doi: http://dx.doi.org/10.1136/bmj.e8501

Laws RA, Kirby SE, Powell-Davies GP, Williams AM, Jayasinghe UW, Amoroso CL, Harris MF 2008 'Should I and can I?': a mixed methods study of clinician beliefs and attitudes in the management of lifestyle risk factors in primary health care. BMC Health Services Research 8: 44

O’Donoghue G, Cunningham C, Murphy F, Woods C, Aagaard-Hansen J 2014 Assessment and management of risk factors for the prevention of lifestyle related disease: a crosssectional survey of current activities, barriers and perceived education needs of primary care physiotherapists in the Republic of Ireland. Physiotherapy 100: 116-122

Pignataro RM, Ohtake PJ, Swisher A, Dino G 2012 The role of physical therapists in smoking cessation: opportunities for improving treatment outcomes. Physical Therapy 92: $757-766$ 
Rea BL, Marshak HH, Neish C, Davis N 2004 The role of health promotion in physical therapy in California, New York, and Tennessee. Physical Therapy 84: 510-523

Rose HL, Miller PM, Nemeth LS, Jenkins RG, Nietert PJ, Wessell A, Ornstein SM 2008 Alcohol screening and brief counseling in a primary care hypertensive population: a quality improvement intervention. Addiction 103: 1271-1280

Saitz R 2010 Alcohol screening and brief intervention in primary care: absence of evidence for efficacy in people with dependence or very heavy drinking. Drug Alcohol Review 29: 631-640

Shirley D, van der Ploeg HP, Bauman AE 2010 Physical activity promotion in the physical therapy setting: perspectives from practitioners and students. Physical Therapy 90: 13111322

Snodgrass SJ, Carter AE, Guest M, Collins CE, James C, Kable AK, Ashby SE, Plotnikoff RC 2014 Weight management including dietary and physical activity advice provided by Australian physiotherapists: a pilot cross-sectional survey. Physiotherapy Theory and Practice 30: $409-420$

The Medical Rehabilitation Therapist Board of Nigeria 2011 The Nigeria Medical Rehabilitation Therapist Bulletin 13: 46-78

World Confederation for Physical Therapy 2014 Network for Health Promotion in Life and Work (NHPLW). http://www.wcpt.org/node/100327

World Health Organization 1998 World Health Assembly resolution WHA51.12 - Health promotion. http://www.who.int/healthpromotion/areas/regions/en/

World Health Organization 2004 Global Forum on Integrated NCD Prevention and Control. Together in Global Action. http://www.who.int/chp/about/global_forum/en/

World Health Organization 2011 WHO Maps: Non-communicable disease trend in all countries. Nigeria. World Health Global Report.

http://www.who.int/nmh/countries/nga_en.pdf?ua=

World Health Organization 2014a Health promotion. Support to regions and countries in health promotion, strengthening national and community capacity.

http://www.who.int/healthpromotion/areas/regions/en/

World Health Organization 2014b Noncommunicable Diseases (NCD) Country Profiles. http://www.who.int

World Health Rankings 2015 Health Profile Nigeria. http://www.worldlifeexpectancy.com/country-health-profile/nigeria 
Table 1. Geographic distribution of respondents from the regions/states in Nigeria (frequency (n) and percentage $(\%))$.

$$
\text { Regions/States } \quad \text { Frequency (n) Percentage (\%) }
$$

$\begin{array}{lcl}\text { South East } & & \\ \text { Abia state } & 9 & 2.0 \\ \text { Anambra } & 14 & 3.1 \\ \text { Ebonyi } & 46 & 10.2 \\ \text { Enugu } & 64 & 14.2 \\ \text { Imo } & 14 & 3.1\end{array}$

South South

$\begin{array}{lll}\text { Delta } & 6 & 1.3 \\ \text { Rivers } & 10 & 2.2 \\ \text { Bayelsa } & 4 & 0.8 \\ \text { Edo } & 8 & 1.8\end{array}$

\section{South West}

$\begin{array}{llr}\text { Lagos } & 37 & 8.2 \\ \text { Ogun } & 49 & 10.7 \\ \text { Ondo } & 28 & 6.2 \\ \text { Oyo } & 16 & 3.5\end{array}$

North Central + Federal Capital Territory

$\begin{array}{lcc}\text { Kogi } & 20 & 4.4 \\ \text { Nassarawa } & 13 & 2.9 \\ \text { Benue } & 9 & 2.0 \\ \text { FCT } & 17 & 3.8\end{array}$

North East

$\begin{array}{lrr}\text { Bauchi } & 12 & 2.7 \\ \text { Zamfara } & 6 & 1.3\end{array}$

North West

$\begin{array}{lcc}\text { Kaduna } & 24 & 5.3 \\ \text { Katsina } & 22 & 4.9 \\ \text { Kano } & 15 & 3.3 \\ \text { Sokoto } & 7 & 1.6\end{array}$

Total

$451 \quad 100$ 
Table 2. Frequency with which respondents assess risk factors in new and follow-up patients (percentage $(\%)$ and frequency $(n))$.

New patients

\begin{tabular}{|l|c|c|c|c|}
\hline & $\begin{array}{c}\text { Never } \\
\%(\mathrm{n})\end{array}$ & $\begin{array}{c}\text { Sometimes } \\
\%(\mathrm{n})\end{array}$ & $\begin{array}{c}\text { Usually } \\
\%(\mathrm{n})\end{array}$ & $\begin{array}{c}\text { Always } \\
\%(\mathrm{n})\end{array}$ \\
\hline Smoking & $4.8(21)$ & $19.5(86)$ & $19.7(87)$ & $56.1(248)$ \\
\hline Diet & $4.1(18)$ & $39.7(174)$ & $26.0(114)$ & $30.1(132)$ \\
\hline $\begin{array}{l}\text { Alcohol } \\
\text { consumption }\end{array}$ & $4.5(20)$ & $18.9(83)$ & $21.1(93)$ & $55.5(244)$ \\
\hline Physical activity & $2.0(9)$ & $27.1(120)$ & $23.1(102)$ & $47.7(211)$ \\
\hline Blood pressure & $1.4(6)$ & $12.0(53)$ & $15.6(69)$ & $71.0(314)$ \\
\hline $\begin{array}{l}\text { Family history of } \\
\text { cardiovascular } \\
\text { disease/diabetes }\end{array}$ & $3.4(15)$ & $19.4(85)$ & $21.9(96)$ & $55.4(243)$ \\
\hline Anthropometrics & $7.3(31)$ & $42.7(182)$ & $23.2(99)$ & $26.8(114)$ \\
\hline
\end{tabular}

Follow-up patients

\begin{tabular}{|l|c|c|c|c|}
\hline & $\begin{array}{c}\text { Never } \\
\%(\mathrm{n})\end{array}$ & $\begin{array}{c}\text { Sometimes } \\
\%(\mathrm{n})\end{array}$ & $\begin{array}{c}\text { Usually } \\
\%(\mathrm{n})\end{array}$ & $\begin{array}{c}\text { Always } \\
\%(\mathrm{n})\end{array}$ \\
\hline Smoking & $13.0(56)$ & $32.4(140)$ & $22.0(95)$ & $32.6(141)$ \\
\hline Diet & $5.6(24)$ & $41.1(177)$ & $30.2(130)$ & $23.2(100)$ \\
\hline Alcohol & & & & $38.1(164)$ \\
\hline consumption & $10.9(47)$ & $29.8(95)$ & $21.1(91)$ & $47.9(206)$ \\
\hline
\end{tabular}




\begin{tabular}{|l|c|c|c|c|}
\hline Blood pressure & $2.5(11)$ & $13.9(60)$ & $20.6(89)$ & $63.0(273)$ \\
\hline $\begin{array}{l}\text { Family history of } \\
\text { cardiovascular } \\
\text { disease/diabetes }\end{array}$ & $10.2(44)$ & $27.9(121)$ & $26.6(115)$ & $35.3(153)$ \\
\hline Anthropometrics & $9.8(41)$ & $40.0(167)$ & $22.3(93)$ & $27.8(116)$ \\
\hline
\end{tabular}

Table 3. Frequency with which respondents engage in key health behavior change practices (assessment of readiness to change, advising patients to change risky behaviors, providing written advice, referral to other services/resources, and accessibility to other resources/providers (percentages (\%) and frequency (n)).

Frequency of assessment of readiness to change

\begin{tabular}{|l|c|c|c|c|}
\hline & $\begin{array}{c}\text { Never } \\
\%(\mathrm{n})\end{array}$ & $\begin{array}{c}\text { Sometimes } \\
\%(\mathrm{n})\end{array}$ & $\begin{array}{c}\text { Usually } \\
\%(\mathrm{n})\end{array}$ & $\begin{array}{c}\text { Always } \\
\%(\mathrm{n})\end{array}$ \\
\hline Smoking & $15.9(70)$ & $28.4(125)$ & $30.5(134)$ & $25.2(111)$ \\
\hline Diet & $8.0(35)$ & $33.3(146)$ & $30.1(132)$ & $28.7(126)$ \\
\hline Alcohol & $12.5(55)$ & $28.0(123)$ & $30.7(135)$ & $28.9(127)$ \\
\hline Physical activity & $4.3(19)$ & $17.9(79)$ & $31.3(138)$ & $46.5(205)$ \\
\hline
\end{tabular}

Frequency participants advise patients to change risky behaviors

\begin{tabular}{|l|c|c|c|c|}
\hline & $\begin{array}{c}\text { Never } \\
\%(\mathrm{n})\end{array}$ & $\begin{array}{c}\text { Sometimes } \\
\%(\mathrm{n})\end{array}$ & $\begin{array}{c}\text { Usually } \\
\%(\mathrm{n})\end{array}$ & $\begin{array}{c}\text { Always } \\
\%(\mathrm{n})\end{array}$ \\
\hline$\downarrow$ Smoking & $6.3(28)$ & $20.5(91)$ & $28.6(127)$ & $44.6(198)$ \\
\hline $\begin{array}{l}\uparrow \text { Vegetables/ } \\
\text { fruit }\end{array}$ & $2.3(10)$ & $19.1(85)$ & $30.0(133)$ & $48.6(216)$ \\
\hline
\end{tabular}




\begin{tabular}{|l|c|c|c|c|}
\hline$\uparrow$ Fiber & $5.4(24)$ & $23.8(106)$ & $34.4(153)$ & $36.4(162)$ \\
\hline $\begin{array}{l}\downarrow \text { Alcohol } \\
\begin{array}{c}\uparrow \text { Physical } \\
\text { activity }\end{array}\end{array}$ & $4.7(21)$ & $20.1(89)$ & $26.2(116)$ & $49.0(217)$ \\
\hline
\end{tabular}

Frequency participants provide written advice

\begin{tabular}{|l|c|c|c|c|}
\hline & $\begin{array}{c}\text { Never } \\
\%(\mathrm{n})\end{array}$ & $\begin{array}{c}\text { Sometimes } \\
\%(\mathrm{n})\end{array}$ & $\begin{array}{c}\text { Usually } \\
\%(\mathrm{n})\end{array}$ & $\begin{array}{c}\text { Always } \\
\%(\mathrm{n})\end{array}$ \\
\hline$\downarrow$ Smoking & $50.8(226)$ & $33.9(151)$ & $7.2(32)$ & $8.1(36)$ \\
\hline Balanced diet & $35.7(159)$ & $38.0(169)$ & $13.5(60)$ & $12.8(57)$ \\
\hline$\downarrow$ Alcohol & $45.6(203)$ & $33.3(146)$ & $8.5(38)$ & $12.6(56)$ \\
\hline $\begin{array}{c}\text { 个 Physical } \\
\text { activity }\end{array}$ & $24.0(107)$ & $33.4(148)$ & $19.3(86)$ & $23.4(104)$ \\
\hline
\end{tabular}

Frequency of referral to other providers or resources

\begin{tabular}{|l|c|c|c|c|}
\hline & $\begin{array}{c}\text { Never } \\
\%(\mathrm{n})\end{array}$ & $\begin{array}{c}\text { Sometimes } \\
\%(\mathrm{n})\end{array}$ & $\begin{array}{c}\text { Usually } \\
\%(\mathrm{n})\end{array}$ & $\begin{array}{c}\text { Always } \\
\%(\mathrm{n})\end{array}$ \\
\hline $\begin{array}{l}\text { Smoking } \\
\text { cessation }\end{array}$ & $51.4(222)$ & $29.2(126)$ & $6.7(29)$ & $12.7(55)$ \\
\hline Dietary & $16.6(72)$ & $34.1(148)$ & $24.7(107)$ & $24.7(107)$ \\
\hline $\begin{array}{l}\text { Alcohol } \\
\text { consumption }\end{array}$ & $48.3(209)$ & $28.9(125)$ & $8.3(36)$ & $14.5(63)$ \\
\hline Physical activity & $18.8(81)$ & $23.0(99)$ & $24.4(105)$ & $33.9(146)$ \\
\hline
\end{tabular}

Frequency with which participants report access to other services and programs 


\begin{tabular}{|l|c|c|c|c|}
\hline Service/Program & Never & Sometimes & Usually & Always \\
& $\%(\mathrm{n})$ & $\%(\mathrm{n})$ & $\%(\mathrm{n})$ & $\%(\mathrm{n})$ \\
\hline Smoking & $46.7(200)$ & $33.2(142)$ & $8.4(36)$ & $11.7(50)$ \\
\hline Dietary advice & $15.0(65)$ & $29.9(126)$ & $26.4(114)$ & $28.7(124)$ \\
\hline Advice alcohol & $43.7(187)$ & $31.8(136)$ & $12.9(55)$ & $11.7(50)$ \\
consumption & & & & \\
\hline Advice physical & $11.4(49)$ & $25.6(110)$ & $19.5(84)$ & \\
Activity & & & & \\
\hline
\end{tabular}


Table 4. Frequency with which respondents manage lifestyle risk factors related to obesity, impaired glucose tolerance, hypertension and hyperlipidemia (percentage (\%) and frequency (n)).

Patients who are obese

\begin{tabular}{|l|c|c|c|c|}
\hline Respondent & $\begin{array}{c}\text { Never } \\
\text { recommendation }\end{array}$ & $\begin{array}{c}\text { Sometimes } \\
\%(\mathrm{n})\end{array}$ & $\begin{array}{c}\text { Usually } \\
\%(\mathrm{n})\end{array}$ & $\begin{array}{c}\text { Always } \\
\%(\mathrm{n})\end{array}$ \\
\hline$\downarrow$ Calories & $1.7(7)$ & $14.5(59)$ & $26.1(106)$ & $57.6(234)$ \\
\hline$\downarrow$ Dietary fat & $2.7(11)$ & $11.4(46)$ & $29.4(119)$ & $56.5(229)$ \\
\hline 个Fiber & $4.2(17)$ & $12.4(50)$ & $27.0(109)$ & $56.4(228)$ \\
\hline Regular exercise & $1.2(5)$ & $3.9(16)$ & $23.0(94)$ & $71.8(293)$ \\
\hline $\begin{array}{l}\text { Set weight loss } \\
\text { goal }\end{array}$ & $5.0(20)$ & $17.9(72)$ & $25.1(101)$ & $52.0(209)$ \\
\hline
\end{tabular}

Patients with glucose intolerance

\begin{tabular}{|l|c|c|c|c|}
\hline Respondent & $\begin{array}{c}\text { Never } \\
\text { recommendation }\end{array}$ & $\begin{array}{c}\text { Sometimes } \\
\%(\mathrm{n})\end{array}$ & $\begin{array}{c}\text { Usually } \\
\%(\mathrm{n})\end{array}$ & $\begin{array}{c}\text { Always } \\
\%(\mathrm{n})\end{array}$ \\
\hline$\downarrow$ Calories & $13.8(52)$ & $25.4(96)$ & $23.8(90)$ & $37.0(140)$ \\
\hline$\downarrow$ Dietary fat & $9.5(36)$ & $25.7(97)$ & $33.2(125)$ & $31.6(119)$ \\
\hline 个Fiber & $8.2(31)$ & $21.1(80)$ & $29.5(112)$ & $41.3(157)$ \\
\hline Regular exercise & $7.3(28)$ & $13.6(52)$ & $29.9(114)$ & $49.1(187)$ \\
\hline $\begin{array}{l}\text { Set weight loss } \\
\text { goal }\end{array}$ & $15.5(59)$ & $24.2(92)$ & $20.5(78)$ & $39.7(151)$ \\
\hline
\end{tabular}

Patients with hypertension

\begin{tabular}{|l|c|c|c|c|}
\hline Respondent & Never & Sometimes & Usually & Always \\
recommendation & $\%(n)$ & $\%(n)$ & $\%(n)$ & $\%(n)$ \\
\hline
\end{tabular}




\begin{tabular}{|l|c|c|c|c|}
\hline$\downarrow$ Calories & $10.2(41)$ & $29.0(117)$ & $21.6(87)$ & $39.2(158)$ \\
\hline$\downarrow$ Dietary fat & $6.7(27)$ & $19.8(80)$ & $29.1(118)$ & $44.4(180)$ \\
\hline$\uparrow$ Fiber & $7.4(30)$ & $16.8(68)$ & $30.9(125)$ & $44.9(182)$ \\
\hline Regular exercise & $2.2(9)$ & $13.6(55)$ & $27.5(111)$ & $56.7(229)$ \\
\hline $\begin{array}{l}\text { Set weight loss } \\
\text { goal }\end{array}$ & $9.5(38)$ & $26.9(108)$ & $18.7(75)$ & $45.0(181)$ \\
\hline
\end{tabular}

Patients with hyperlipidemia

\begin{tabular}{|l|c|c|c|c|}
\hline $\begin{array}{l}\text { Respondent } \\
\text { recommendation }\end{array}$ & $\begin{array}{c}\text { Never } \\
\%(\mathrm{n})\end{array}$ & $\begin{array}{c}\text { Sometimes } \\
\%(\mathrm{n})\end{array}$ & $\begin{array}{c}\text { Usually } \\
\%(\mathrm{n})\end{array}$ & $\begin{array}{c}\text { Always } \\
\%(\mathrm{n})\end{array}$ \\
\hline$\downarrow$ Calories & $11.8(46)$ & $22.3(87)$ & $27.6(108)$ & $38.4(150)$ \\
\hline$\downarrow$ Dietary fat & $7.9(31)$ & $17.3(68)$ & $31.0(122)$ & $43.8(172)$ \\
\hline$\uparrow$ Fiber & $8.7(34)$ & $17.9(70)$ & $30.7(129)$ & $42.7(167)$ \\
\hline Regular exercise & $5.3(21)$ & $11.4(45)$ & $32.2(127)$ & $51.0(201)$ \\
\hline $\begin{array}{l}\text { Set weight loss } \\
\text { goal }\end{array}$ & $9.9(39)$ & $24.2(95)$ & $21.7(85)$ & $44.1(173)$ \\
\hline
\end{tabular}


Table 5. Respondents' views about the importance of lifestyle counseling, its priority, and patient acceptance (percentage (\%) and frequency (n)).

Importance to respondents of counseling patients with risk factors:

\begin{tabular}{|l|c|c|c|c|}
\hline & $\begin{array}{c}\text { Very important } \\
\%(\mathrm{n})\end{array}$ & $\begin{array}{c}\text { Moderately } \\
\text { important } \\
\%(\mathrm{n})\end{array}$ & $\begin{array}{c}\text { Somewhat } \\
\text { important } \\
\%(\mathrm{n})\end{array}$ & $\begin{array}{c}\text { Not at all } \\
\text { important } \\
\%(\mathrm{n})\end{array}$ \\
\hline $\begin{array}{l}\text { Smoking } \\
\text { cessation }\end{array}$ & $86.1(373)$ & $7.2(31)$ & $3.0(13)$ & $3.7(16)$ \\
\hline Healthy diet & $85.5(372)$ & $11.3(49)$ & $1.4(6)$ & $1.8(8)$ \\
\hline $\begin{array}{l}\text { Alcohol } \\
\text { moderation }\end{array}$ & $79.4(343)$ & $13.2(57)$ & $3.9(17)$ & $3.5(15)$ \\
\hline $\begin{array}{l}\text { Physical } \\
\text { activity/exercise }\end{array}$ & $84.4(367)$ & $9.7(42)$ & $2.8(12)$ & $3.2(14)$ \\
\hline
\end{tabular}

Professional priority reported by respondents to address lifestyle risk factors:

\begin{tabular}{|l|c|c|c|c|}
\hline & $\begin{array}{c}\text { High } \\
\%(\mathrm{n})\end{array}$ & $\begin{array}{c}\text { Moderate } \\
\%(\mathrm{n})\end{array}$ & $\begin{array}{c}\text { Somewhat } \\
\%(\mathrm{n})\end{array}$ & $\begin{array}{c}\text { Low } \\
\%(\mathrm{n})\end{array}$ \\
\hline $\begin{array}{l}\text { Smoking } \\
\text { cessation }\end{array}$ & $62.4(269)$ & $27.1(117)$ & $7.2(31)$ & $3.2(14)$ \\
\hline Healthy diet & $68.0(293)$ & $24.8(107)$ & $6.0(26)$ & $1.2(5)$ \\
\hline $\begin{array}{l}\text { Alcohol } \\
\text { moderation }\end{array}$ & $60.9(262)$ & $27.0(116)$ & $8.8(38)$ & $3.3(14)$ \\
\hline $\begin{array}{l}\text { Physical } \\
\text { activity/exercise }\end{array}$ & $75.2(324)$ & $19.3(83)$ & $4.2(18)$ & $1.4(6)$ \\
\hline
\end{tabular}

Respondents' perceived patient acceptance of lifestyle counseling

\begin{tabular}{|l|l|l|l|l|}
\hline & Very important & Moderately & Somewhat & Not at all \\
\hline
\end{tabular}




\begin{tabular}{|l|c|c|c|c|}
\hline & $\%(\mathrm{n})$ & $\begin{array}{c}\text { important } \\
\%(\mathrm{n})\end{array}$ & $\begin{array}{c}\text { important } \\
\%(\mathrm{n})\end{array}$ & $\begin{array}{c}\text { important } \\
\%(\mathrm{n})\end{array}$ \\
\hline $\begin{array}{l}\text { Smoking } \\
\text { cessation }\end{array}$ & $35.9(152)$ & $42.8(181)$ & $18.7(79)$ & $2.6(11)$ \\
\hline Healthy diet & $56.3(241)$ & $33.7(144)$ & $10.0(43)$ & $0.0(0)$ \\
\hline $\begin{array}{l}\text { Alcohol } \\
\text { moderation }\end{array}$ & $32.2(136)$ & $39.5(167)$ & $25.8(109)$ & $2.6(11)$ \\
\hline $\begin{array}{l}\text { Physical } \\
\text { activity/exercise }\end{array}$ & $54.3(232)$ & $35.8(153)$ & $8.9(38)$ & $0.9(4)$ \\
\hline
\end{tabular}


Table 6. Respondents' ratings of lifestyle counseling competencies (performance confidence and perceived effectiveness (percentages (\%) and frequency (n)).

Respondents' confidence in conducting the following activities

\begin{tabular}{|l|c|c|c|c|}
\hline & $\begin{array}{c}\text { Very confident } \\
\%(\mathrm{n})\end{array}$ & $\begin{array}{c}\text { Moderately } \\
\text { confident } \\
\%(\mathrm{n})\end{array}$ & $\begin{array}{c}\text { Somewhat } \\
\text { confident } \\
\%(\mathrm{n})\end{array}$ & $\begin{array}{c}\text { Not at all } \\
\text { confident } \\
\%(\mathrm{n})\end{array}$ \\
\hline $\begin{array}{l}\text { Assessing } \\
\text { nicotine } \\
\text { dependence }\end{array}$ & $34.1(141)$ & $31.4(130)$ & $22.0(91)$ & $12.6(52)$ \\
\hline $\begin{array}{l}\text { Assessing } \\
\text { nutritional status }\end{array}$ & $50.0(209)$ & $31.6(132)$ & $15.6(65)$ & $2.9(12)$ \\
\hline $\begin{array}{l}\text { Assessing risky } \\
\text { drinking }\end{array}$ & $42.4(177)$ & $36.5(152)$ & $15.6(65)$ & $5.5(23)$ \\
\hline $\begin{array}{l}\text { Assessing } \\
\text { physical } \\
\text { activity/exercise }\end{array}$ & $69.7(290)$ & $23.3(97)$ & $5.5(23)$ & $1.4(6)$ \\
\hline $\begin{array}{l}\text { Motivational } \\
\text { interviewing }\end{array}$ & $58.7(244)$ & $29.8(124)$ & $9.6(40)$ & $1.9(8)$ \\
\hline $\begin{array}{l}\text { Assessing } \\
\text { readiness to } \\
\text { change }\end{array}$ & $49.2(204)$ & $36.1(150)$ & $12.5(52)$ & $2.2(9)$ \\
\hline $\begin{array}{l}\text { Assessing } \\
\text { absolute cardiac } \\
\text { risk }\end{array}$ & $48.6(202)$ & $34.9(145)$ & $13.0(54)$ & $3.6(15)$ \\
\hline
\end{tabular}

Respondents' perceived effectiveness of advising patients to change unhealthy behaviors

\begin{tabular}{|c|c|c|c|c|}
\hline & $\begin{array}{c}\text { Very effective } \\
\%(\mathrm{n})\end{array}$ & $\begin{array}{c}\text { Moderately } \\
\text { effective }\end{array}$ & $\begin{array}{c}\text { Somewhat } \\
\text { effective }\end{array}$ & $\begin{array}{c}\text { Not at all } \\
\text { effective }\end{array}$ \\
& & $\%(\mathrm{n})$ & $\%(\mathrm{n})$ & $\%(\mathrm{n})$ \\
\hline
\end{tabular}




\begin{tabular}{|l|c|c|c|c|}
\hline $\begin{array}{l}\text { Smoking } \\
\text { cessation }\end{array}$ & $47.6(202)$ & $45.0(191)$ & $3.8(16)$ & $3.5(15)$ \\
\hline Unhealthy diet & $59.1(251)$ & $38.8(165)$ & $0.9(4)$ & $1.2(5)$ \\
\hline $\begin{array}{l}\text { Excessive } \\
\text { alcohol }\end{array}$ & $45.5(193)$ & $47.6(202)$ & $4.5(19)$ & $2.4(10)$ \\
\hline Inactivity & $71.2(304)$ & $27.9(119)$ & $0.2(1)$ & $0.7(3)$ \\
\hline
\end{tabular}


Table 7. Respondents' perceived barriers to effecting lifestyle behavior change (percentages (\%) and frequency (n)).

\begin{tabular}{|l|c|c|c|c|}
\hline & $\begin{array}{c}\text { Significant } \\
\text { barrier } \\
\%(\mathrm{n})\end{array}$ & $\begin{array}{c}\text { Somewhat of a } \\
\text { barrier } \\
\%(\mathrm{n})\end{array}$ & $\begin{array}{c}\text { Not a barrier } \\
\%(\mathrm{n})\end{array}$ & Not applicable \\
\hline Lack of time & $31.0(130)$ & $30.3(127)$ & $34.1(143)$ & $4.5(19)$ \\
\hline $\begin{array}{l}\text { Lack of access to } \\
\text { counselors }\end{array}$ & $27.6(116)$ & $37.1(156)$ & $32.6(137)$ & $2.6(11)$ \\
\hline $\begin{array}{l}\text { Personal lack of } \\
\text { interest }\end{array}$ & $16.2(68)$ & $18.6(78)$ & $51.7(217)$ & $13.6(57)$ \\
\hline $\begin{array}{l}\text { Patient lack of } \\
\text { interest }\end{array}$ & $27.3(115)$ & $39.7(167)$ & $23.5(99)$ & $9.5(40)$ \\
\hline $\begin{array}{l}\text { Lack of } \\
\text { confidence about } \\
\text { services needed }\end{array}$ & $14.9(62)$ & $24.0(100)$ & $44.1(184)$ & $17.0(71)$ \\
\hline $\begin{array}{l}\text { Lack of } \\
\text { educational } \\
\text { materials }\end{array}$ & $28.3(119)$ & $48.8(205)$ & $18.6(78)$ & $4.3(18)$ \\
\hline \begin{tabular}{l} 
Lack of expertise \\
\hline
\end{tabular} & $26.3(110)$ & $27.5(115)$ & $37.1(155)$ & $9.1(38)$ \\
\hline
\end{tabular}

